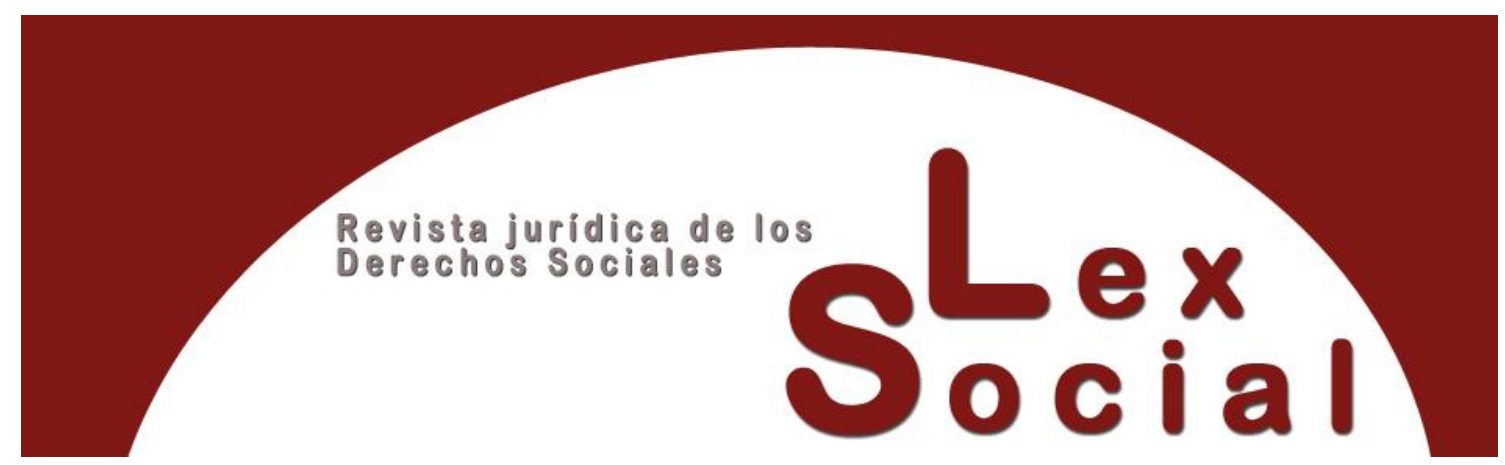

\title{
ANÁLISIS JURÍDICO-LABORAL DEL TRÁFICO ILEGAL DE MANO DE OBRA MEDIANTE UN DISEÑO OBSERVACIONAL
}

\section{LEGAL-LABOUR ANALYSIS OF ILLEGAL LABOUR TRAFFICKING USING AN OBSERVATIONAL DESIGN}

\author{
ANTONIO MEGÍAS-BAS \\ Profesor Ayudante Doctor de Derecho del Trabajo y de la Seguridad Social \\ Universidad de Vigo \\ https://orcid.org/0000-0003-3304-8142
}

Cómo citar este trabajo: Megías-Bas, A. (2022). Análisis jurídico-laboral del tráfico ilegal de mano de obra mediante un diseño observacional. Lex Social: Revista De Derechos Sociales, 12 (1), pp. 143-165. https://doi.org/10.46661/lexsocial.6433

\begin{abstract}
RESUMEN
Esta investigación tiene como punto de partida el análisis jurídico-laboral del artículo 312.1 del Código Penal de España; acudimos a la doctrina iuslaboral y penal que lo examina, así como a las sentencias sobre tráfico ilegal de mano de obra. Pretendemos conocer qué interpretan los jueces, juezas y tribunales del orden penal que es el tráfico ilegal de mano de obra. Para ello, identificamos los elementos significativos que aparecen en los fundamentos jurídicos de las sentencias, cuando analizan el delito, para diferenciarlo de la infracción administrativo-laboral. También buscamos las coincidencias y diferencias entre la interpretación judicial y la académica sobre tráfico ilegal de mano de obra. Realizamos un diseño observacional y no experimental para el estudio de estas, recogiendo la información en un protocolo de observación sistemática, con distintas categorías, construido "ad hoc". Los datos muestran, por ejemplo, que existen desajustes entre la interpretación académica y la judicial, así como la falta de concreción respecto al bien jurídico protegido.
\end{abstract}

\section{$(c))$ EY-NC-SA}


Palabras Clave: Tráfico ilegal de mano de obra, cesión ilegal, intermediación laboral, análisis cuantitativo, sentencias, diseño observacional y no experimental

\begin{abstract}
The starting point for this research is the legal-labour analysis of article 312.1 of the Spanish Criminal Code; we turn to the labour and criminal law doctrine that examines it, as well as to judgments on illegal labour trafficking. Our aim is to find out what judges and criminal courts interpret illegal labour trafficking to mean. To do this, we identified the significant elements that appear in the legal grounds of the judgements, when they analyse the crime, to differentiate it from the administrativelabour offence. We also looked for coincidences and differences between judicial and academic interpretations of illegal labour trafficking. We carried out an observational and non-experimental design for the study of these, collecting the information in a systematic observation protocol, with different categories, constructed "ad hoc". The data show, for example, that there are mismatches between academic and judicial interpretation, as well as a lack of specificity with respect to the protected legal right.
\end{abstract}

KEYWORDS: Illegal labour trafficking, illegal labour transfer, labour brokering, quantitative analysis, judgements, observational and non-experimental design.

SUMARIO

I. Introducción: breves apuntes sobre el marco legal y doctrinal del tráfico ilegal de mano de obra.

II. Investigación documental sobre el Tráfico ilegal de mano de obra.

1. Metodología y procedimiento.

1.1. Enfoque y diseño de la investigación.

1.2. Participantes y contexto.

1.3. Recogida de información: instrumentos y procedimientos.

1.4. Instrumentos y procedimiento.

1.4.1. Protocolo de Observación Documental Sistemático (PODS).

III. Análisis de los resultados sobre las sentencias.

IV. Conclusiones y propuestas.

Bibliografía. 


\section{Introducción: breves apuntes sobre el marco legal y doctrinal del tráfico ilegal de mano de obra}

En la actual sociedad globalizada las empresas pueden descentralizar su producción ${ }^{1}$, buscando una mayor rentabilidad económica en lugares más condescendientes con sus intereses, provocando, en ocasiones, circunstancias de dumping social ${ }^{2}$. Las empresas, por un lado, al marcharse de zonas geográficas, generan un incremento de la precariedad laboral y, por consiguiente, se acrecienta el riesgo de exclusión social, así como de los niveles de pobreza, que debe ser mitigado con políticas sociales ${ }^{3}$. Por otro lado, en las zonas en las que se instalan pueden utilizar estrategias comerciales para abaratar costes en ese lugar ${ }^{4}$. Por ello, las unidades productivas descentralizadas pueden dar lugar, por diferentes motivos, a condiciones laborales precarias sobre las personas que emplean. Lo

\footnotetext{
${ }^{1}$ Esta forma de concebir la organización productiva ha sido denominada como la "cuarta revolución industrial" (SCHWAB, K. La cuarta revolución industrial. Debate, 2016). Este modelo también es utilizado por la administración pública, por ejemplo, en el proceso de digitalización cuyo modelo de gobernanza mediante Tecnologías de la Información y de la Comunicación (TIC) comenzó a implantarse mediante la Ley 11/2007, de 22 de junio, de acceso electrónico de los ciudadanos a los servicios públicos, ya que "la Administración digital española está llamada a convertirse en una realidad más pronto que tarde, ante el riesgo de quedar más desfasados respecto de los países vecinos", en RODRIGUEZ RODRIGUEZ, E., "La subrogación empresarial en los procesos de reversión de contratas y concesiones administrativas ante una administración pública digitalizada". Pertsonak eta Antolakunde Publikoak Kudeatzeko Euskal Aldizkaria = Revista Vasca de Gestión de Personas y Organizaciones Públicas, 2019, no 17, p. 55.

${ }^{2}$ La RAE define dumping como la "práctica comercial de vender a precios inferiores al costo, para adueñarse del mercado, con grave perjuicio de este" (http://dle.rae.es/?id=EGMv5mz) y el "dumping social" como "prácticas legales o administrativas que reducen los niveles de protección de los trabajadores, produciendo un correlativo abaratamiento de los costes laborales, con vistas a favorecer la inversión extranjera y la exportación" https://dpej.rae.es/lema/dumping-social, consultado el 5 de diciembre de 2020. ${ }^{3}$ Algunos autores hablan de "pobreza laboriosa" al referirse a la degradación de las condiciones laborales provocada por la descentralización productiva. Véase: RODRIGUEZ-PIÑERO y BRAVO-FERRER, M., "Trabajadores pobres y Derecho del Trabajo, Relaciones Laborales, $\mathrm{n}^{\circ} .2$, 2009, p. 27; MARTINEZ MORENO, C. "El riesgo de exclusión social de los trabajadores pobres: análisis de las reglas jurídicas conectadas con este nuevo fenómeno", en MORENO I GENÉ, J. (dir.), FERNÁNDEZ VILLAZÓN, L. A. (dir.), Crisis de empleo, integración y vulnerabilidad social, Thomson Reuters Aranzadi, Cizur Menor, Navarra, 2017, pp. 181-216; MONEREO PEREZ, J. L., "La garantía de los derechos de los trabajadores en la subcontratación empresarial, Derecho de las Relaciones Laborales, $\mathrm{n}^{\circ}$. 2, 2016, p. 116. Debemos destacar las palabras de la profesora López Aniorte: "entraríamos de lleno dentro de la denominada "versión patológica" de la descentralización productiva, encaminada a la reducción de costes empresariales mediante la interposición de un tercero en el lugar del verdadero empresario, con el fin de eludir la aplicación al trabajador de las normas que le resultan más favorables", en LÓPEZ ANIORTE, M ${ }^{\mathrm{a}}$. C., La descentralización productiva y su incidencia en la relación individual de trabajo, Laborum, Murcia, 2003. ${ }^{4}$ Esta situación se manifiesta, por ejemplo, a través de las denominadas "empresas maquiladoras" (las "maquiladoras", originadas en México, son empresa que importan materiales sin pagar aranceles y comercializan sus productos en el país de origen de la materia prima), que son utilizadas en las estrategias descentralizadoras de los países desarrollados para abaratar costes laborales. Su impacto en países menos desarrollados, como es el caso de los países centroamericanos, ha tenido efectos negativos sobre las condiciones laborales. En este sentido, GOLDIN, A., "La problemática laboral de la descentralización productiva y la transformación del Derecho del Trabajo", en MONEREO PÉREZ, J. L. y PERÁN QUESADA, S. (dirs.), La externalización productiva a través de la subcontratación empresarial, Comares, Granada, 2018, p. 30; GOLDIN, A., La libertad sindical y las iniciativas voluntarias; el caso de Jerzees de Honduras, en GORELLI HERNANDEZ, J., (coord.), El Derecho a la negociación colectiva" Liber Amicorum Profesor Antonio Ojeda Avilés, Colección Monografías de Temas Laborales, Consejo Andaluz de Relaciones Laborales, Junta de Andalucía, Sevilla, 2014, p. 191.
} 
cierto es que, por una razón u otra, con la descentralización productiva se asume el riesgo del impacto negativo en el empleo y en las condiciones laborales ${ }^{5}$.

Las situaciones de vulnerabilidad en las que se encuentran las personas sin empleo, o con uno precario ${ }^{6}$, unido al riesgo de exclusión social, propician que puedan ser víctimas de irregularidades de distinta índole, como por ejemplo, de contratación laboral e intermediación laboral irregular y, en los casos más graves, en víctimas de delitos contra los derechos de las personas trabajadoras, como el tráfico ilegal de mano de obra; realidades contra las que es preciso intervenir porque, por una parte, atentan contra sus derechos laborales y, por otra, repercuten en el interés del Estado en proteger el mercado laboral ${ }^{7}$ así como en las arcas del mismo, que son el soporte del Estado de bienestar ${ }^{8}$.

Partiendo del contexto mencionado, analizamos una de las vías que tienen las empresas para efectuar la externalización productiva: la cesión de mano de obra. Observamos la ley y la conceptualización efectuada por la doctrina académica y por la jurisprudencia, respecto a la cesión ilegal o tráfico prohibido de mano de obra (art. 43. 2, 3 y 4 Estatuto de los Trabajadores, ET). En este sentido, la doctrina iuslaboralista sostiene que dicho ilícito se puede perseguir penalmente por el delito de tráfico ilegal de mano de obra, tipificado en el art. 312.1 del Código Penal (CP). Desde su origen, se ha planteado un

\footnotetext{
${ }^{5}$ En este sentido, consideramos, como ha manifestado la doctrina científica, "que el trabajo coincide con la misma personalidad humana, no existe acto ni situación en que ésta se halle empeñada que no origine un problema del trabajo", en DE RUGGIERO, G., El concepto del trabajo y su génesis histórica, La Pleyade, Buenos Aires, 1973, p. 97.

${ }^{6}$ La contratación temporal actúa como amortiguador de las crisis de empleo, llevada a cabo, en ocasiones, la contratación temporal de forma directa y, en otras, a través de empresas de trabajo temporal. "Ciertas reformas que han favorecido una y otra se han diseñado precisamente para que las empresas sortearan con más flexibilidad las épocas recesivas. Lo que sucede es que este "parachoques" es mucho más amplio en España, de modo que, en realidad, no funciona como tal, sino que produce el efecto de pérdida de muchos más puestos de trabajo que en los marcos de comparación que puedan contrastarse. Es decir, cuando el empleo se contrae, se denuncian muchos más contratos de los que sería adecuado extinguir, porque la "flexibilidad de salida" resulta mucho más segura, más expeditiva e incluso más económica que la flexibilidad interna. A lo que habría que añadir que se produce una amortización de puestos de trabajo "por exceso", acompañándola de otras medidas de reorganización de la actividad con la plantilla restante. Consecuentemente, el problema del modelo español no está en la debilidad de las medidas de flexibilidad interna, sino en la mayor fortaleza de la "de salida"” CARDONA RUBERT, B. y CABEZA PEREIRO, J. El gran pacto social que debería esperar. LABOS Revista de Derecho del Trabajo y Protección Social, 2021, vol. 2, no 1, p. 125.

${ }^{7}$ La doctrina académica ha entendido que los tipos penales recogidos en el art. 312 y $312 \mathrm{CP}$ hacen referencia a bienes jurídicos estatales ya que su finalidad es proteger la regulación sobre inmigración y mano de obra. En este sentido, NAVARRO CARDOSO, F., Los delitos contra los derechos de los trabajadores, Tirant lo Blach, Valencia, 1998, p. 80.

${ }^{8}$ Alain Supiot considera que "más que hablar de Estado de bienestar (audaz traducción latina de Welfare) o Estado-Providencia (que implica una transcendencia y una unilateralidad poco propias de la exactitud de las construcciones del derecho social), habría que hablar aquí de Estado Social, es decir, de la parte que asume el derecho y las instituciones del Estado en la construcción del vínculo social desde hace ya un siglo. Oponiéndose a la vez al Estado gendarme (o mínimo), en cuanto simple arbitro de las relaciones sociales en las que él no participa directamente, y al Estado Leviathan, en cuanto éste pretende engullirse la sociedad entera, el Estado social participa activamente en el juego social, del que admite no ser él el único dueño", en MARZAL, A. (ed.). Crisis del estado del bienestar y derecho social. José María Bosch, 1997, P. 19. En este sentido, véase: R. Castel, Les metamorphoses de la question sociale. Chronique du salariat, Paris, Fayard, 1995. p. 278 y ss.
} 
debate acerca de la configuración de la cesión ilegal de mano de obra ${ }^{9}$, generándose cierta polémica, la cual surgió bajo la anterior redacción del art. 43 ET y que se mantiene en la actual redacción ${ }^{10}$. Al no estar descrito el ilícito, de forma lo suficientemente precisa, las soluciones ofrecidas, tanto por la doctrina científica como por la jurisprudencia, han sido, en ocasiones, contradictorias ${ }^{11}$. A priori, la doctrina científica se ha pronunciado principalmente entendiendo el carácter objetivo de la prohibición, mientras que los tribunales, en ocasiones, han añadido al incumplimiento laboral requisitos adicionales de motivación $^{12}$. En nuestra opinión, es desacertado incluir requisitos de motivación; el mero incumplimiento de la prohibición conlleva la sanción laboral, mediante la aplicación del art. 8.2 y 18.2.c) LISOS, como precisó la Sala de lo Social del TS en su sentencia de 25 de junio de $2009^{13}$.

Los preceptos contemplados, en el Titulo XV del CP, describen actos o incumplimientos del ámbito laboral que, por su trascendencia, merecen la reacción por parte de la jurisdicción penal ${ }^{14}$. Por tanto, una nota característica diferenciadora del tipo penal frente a la infracción administrativa es la gravedad del hecho atendiendo a la ofensividad y

\footnotetext{
${ }^{9}$ En este sentido, el Grupo de Investigación PAI SEJ-322, Departamento Antón Menger, Universidad de Huelva, señala: "Sin embargo, el propósito del legislador de 1994 se vio pronto superado por los acontecimientos; las fronteras entre las formas legales e ilegales de cesión de trabajadores se diluían en una multiplicidad de fenómenos variables que iban desde la más pura cesión ilegal del artículo 43 a los supuestos de cesión mediante contratas y subcontratas de obras o servicios basados en el régimen jurídico del artículo 42 ET. A los pocos años de vigencia de la reforma, Cruz Villalón podría hablar de «la permanente complejidad de las relaciones triangulares de trabajo»; y el artículo 43 ET no estaba en condiciones de darle respuesta"; "Sin embargo, pronto se pudo observar cómo la aparición de nuevos fenómenos organizativos, bajo la apariencia de contratas y subcontratas de obras y servicios que en ocasiones encubrían auténticas cesiones de mano de obra, provocaban de nuevo el debate sobre las fronteras entre las relaciones triangulares de trabajo legales e ilegales", en PÉREZ GUERRERO, Ma . L. y RODRÍGUEZ-PIÑERO ROYO, M., "El artículo 43 del Estatuto de los Trabajadores: Empresas de trabajo temporal y cesión de trabajadores", Revista del Ministerio de Empleo y Seguridad Social, ${ }^{\circ} .128$, (Ejemplar dedicado a: Derecho del Trabajo. La Inspección de Trabajo y Seguridad Social), 2017, p. 19 y pp. 23-24, http://vlex.com/vid/43-estatuto-trabajadores-temporal-288105, en línea, consultado el 27 de marzo de 2021. También: CRUZ VILLALÓN, J., "La permanente complejidad de las relaciones triangulares de trabajo", Temas Laborales, $\mathrm{n}^{\circ} .56,2000$, p. 1.

10 Véase, en este sentido, CRUZ VILlaLÓN, J., (dir.), GARCIA-PERROTE ESCARTÍN, I. (dir.), GOERLICH PESET, J. Ma . (dir.), MERCADER UGUINA, J. R. (dir.), Comentarios al Estatuto de los Trabajadores, cit., p. 543. También, OLMO GASCÓN, A. M., "El marco normativo de la cesión ilegal de trabajadores como referente y origen del tráfico ilegal de mano de obra", VLex, 2016, p. 24, http://vlex.com/vid/marco-normativo-cesion-ilegal-679296353, en línea, 27 de marzo de 2021.

${ }^{11}$ En este sentido, De Vicente Martínez ha manifestado que la coexistencia de sanciones administrativas y penales sobre un mismo hecho está propiciado por "la defectuosa o nula articulación de los instrumentos previstos legalmente, puesto que el Ordenamiento penal y el Ordenamiento sancionador administrativo caminan a la vez, pero sin mirarse entre sí para nada, evidenciando la nula articulación jurídica de ambas esferas", en DE VICENTE MARTÍNEZ, R., Derecho penal del trabajo: los delitos contra los derechos de los trabajadores y contra la Seguridad Social. Tirant lo Blanch, 2020, p. 78.

${ }^{12}$ OLMO GASCÓN, A. M., "El marco normativo de la cesión ilegal de trabajadores como referente y origen del tráfico ilegal de mano de obra", cit., pp. 29 y 41, http://vlex.com/vid/marco-normativo-cesionilegal-679296353, en línea, 27 de marzo de 2021.

${ }^{13}$ STS (Social) 25/06/2009, $\mathrm{n}^{\circ}$ rec. 57/2008.

${ }^{14}$ En el Diario de Sesiones del día 6 de junio de 1995 consta la intervención en la Comisión del Congreso de los Diputados, encargada de elaborar el Código Penal, del ponente del Partido Socialista Obrero Español, Sr. Navarrete Merino, en la que manifiesta que "el proyecto, en definitiva, tal y como está configurado, protege los siguientes intereses: genéricamente, la vulneración de las condiciones laborales y de Seguridad Social; la correcta contratación de mano de obra".
} 
lesividad ${ }^{15}$ de este, que dotan de significatividad la protección penal ${ }^{16}$. La existencia de una amplia normativa administrativo-laboral protectora de los derechos de las personas asalariadas no es óbice para que algunas violaciones de derechos de este colectivo sean, por su especial relevancia, tipificadas en el Código Penal y sancionadas por la jurisdicción penal $^{17}$. No obstante, este hecho no debe suponer una vulneración del principio "non bis in ídem" ya que los hechos, en ocasiones, serán sancionados en atención a la LISOS y, cuando reúnan los requisitos necesarios, por el CP. De acuerdo con el Derecho penal laboral, el delito de tráfico ilegal de mano de obra sanciona la contratación de personas trabajadoras que se realice al margen de la normativa reguladora ${ }^{18}$, distinguiéndose dos conductas típicas: la cesión ilegal de mano de obra y la colocación laboral irregular ${ }^{19}$. Ahora bien, ¿cuándo deben ser esas conductas sancionadas administrativamente y cuándo penalmente?

Como defiende Mir Puig, "el Derecho penal ha de ser la última ratio, el último recurso a utilizar a falta de otros menos lesivos". Evidentemente, el Derecho Penal ha de ser subsidiario del Derecho sancionador laboral y ha de intervenir sólo en los supuestos en los que los derechos laborales se vean gravemente afectados. En todo momento se ha de tener presente el principio de intervención mínima, buscando el bien social con el menor coste. En este sentido, debemos señalar, como ha manifestado la doctrina científica, que la necesidad de tutelar un bien jurídico, en este caso la relación laboral, requiere que la respuesta normativa sea además de garantista, eficaz, por lo que la tipificación ha de ser clara para no generar problemas interpretativos o aplicativos del tipo. El bien tutelado ha de gozar de significatividad para ser considerado "interés de primera magnitud", siendo por tanto meritorio de protección penal y no meros ilícitos administrativo-laborales

\footnotetext{
${ }^{15}$ La doctrina académica ha utilizado distintos criterios para concretar el grado de lesividad, como la puesta en peligro de los derechos de las personas trabajadoras, NAVARRO CARDOSO, F., Los delitos contra los derechos de los trabajadores, cit., p. 81; obstaculización de las políticas públicas de empleo, TERRADILlOS BASOCO, J. M., Derecho penal de la empresa, Trotta, Madrid, 1995, p. 106, también, VILLACAMPA ESTIARTE, C. y SALAT PAISAL, M., en Quintero Olivares (Dir.) Morales Prats (Coord.) Comentarios a la Parte Especial del Derecho Penal, 10 a ed., Aranzadi, Pamplona, 2015, p. 1169; que la acción llevada a cabo ponga en peligro los derechos de otras personas trabajadoras, CARBONELL MATEU, J.C. y GONZÁLEZ CUSSAC, J. L., en Vives Antón (Coord.), Comentarios al Código Penal de 1995, Tirant lo Blanch, Valencia, 1996, p. 1551; o el plus respecto al ilícito administrativo es lo que delimita el mero hecho aislado de mediación en una colocación y la constitución de un de un negocio lucrativo estable, GARCÍA ARÁN, M., en Córdoba Roda/García Arán (Dirs.), Comentarios al Código Penal. Parte Especial, Tomo I, Marcial Pons, Madrid, 2004, pp. 1278-1279.

${ }^{16}$ En este sentido, GUIRAO SORIANO, P., "La protección penal de los derechos del socio. Crítica y derecho comparado", en III Jornadas doctorales de la UM, EDITUM, Murcia, 2017, p. 367, quien considera que "el hecho de que se tipifique sobre la base de la lesión de bienes jurídicos no lo es todo en orden a gozar de un Derecho Penal de buena salud, pues los bienes jurídicos han de tener relevancia penal (significatividad) para tener acceso al Código Penal".

${ }^{17}$ El hecho de que existan sanciones administrativas y penales sobre un mismo hecho ha dado lugar a numerosos debates, ya que existen dos ramas del ordenamiento jurídico que abordan su regulación y sanción. En este sentido, véase MATTES, H.; MATTES, H.; RODRÍGUEZ DEVESA, J. M., Problemas de derecho penal administrativo: historia y derecho comparado. Editoriales de Derecho Reunidas, 1979.

18 García Arán considera que el termino "mano de obra" integra, además del sujeto pasivo, al objeto del delito, en GARCÍA ARÁN, M., en Córdoba Roda/García Arán (Dirs.), Comentarios al Código Penal. Parte Especial, cit., pp. 1275.

${ }^{19}$ BAYLOS GRAU, A. y TERRADILLOS BASOCO, J. M., Derecho penal del trabajo, $2^{\text {a }}$ Edición revisada, Trotta, Madrid, 1997, p. 84; y, SAP de 10 de noviembre de 1998, n 442/1998, entre otras.
} 
criminalizados $^{20}$. La imprecisión en la redacción del art. 312.1 CP ha provocado que se ponga en entredicho el principio de ofensividad. Por ello, observaremos en los fundamentos de derecho de las sentencias analizadas el bien juridico protegido.

El objeto de estudio es el art. 312.1 CP, donde se dispone que "serán castigados con las penas de prisión de dos a cinco años y multa de seis a doce meses, los que trafiquen de manera ilegal con mano de obra". Se trata de un delito autónomo, diferente del delito de migraciones fraudulentas o clandestinas, y del de trata de seres humanos con finalidad de explotación laboral. Este tipo penal procede del derogado art. 499 bis. 3 CP de 1973. En él se describían dos conductas diferentes; por un lado, se castigaba con arresto mayor y multa a quien traficara de cualquier manera ilegal con la mano de obra. La doctrina científica consideró, en atención a la regulación del CP 1973, que dicha expresión debía ser entendía como traficar al margen de las oficinas de empleo, monopolio entonces del Estado, prohibiendo, consecuentemente, los mecanismos de intermediación en el mercado de trabajo ${ }^{21} \mathrm{y}$, además, la cesión ilegal de mano de obra ${ }^{22}$. Al eliminarse, con la reforma del mercado laboral de 1994, el monopolio público de colocación, legalizándose, asimismo, las agencias privadas de colocación, en primer lugar, sin fines lucrativos y, en la actualidad, también con ánimo de lucro y emitiendo una mera declaración de responsabilidad para llevar a cabo su actividad, y al reconocerse las empresas de trabajo temporal (ETT) como vía para la cesión legal de personas trabajadoras, se alteraron sustancialmente las premisas prohibidas por el tipo penal ${ }^{23}$. Por otro lado, el precepto penal castigaba la cesión de mano de obra que de "forma maliciosa" suprimiera o restringiera "los beneficios de la estabilidad en el empleo y demás condiciones de trabajo reconocidas a los trabajadores por disposiciones legales".

Por ello, tras las distintas reformas laborales, consideramos que los comportamientos tipificados en los preceptos administrativo-laborales que pueden ser susceptibles de ser juzgados por tráfico ilegal de mano de obra serían las tipificadas en los arts. 16.1.a), 16.2.b) y de la Ley de Infracciones y Sanciones del Orden Social (LISOS). Además, en atención al bien jurídico protegido en el tipo penal, la protección de la indemnidad de la relación laboral, proponemos otros supuestos que deben ser contemplados como tráfico ilegal de mano de obra, que son los incumplimientos de los arts. 5 c) RDAC y los arts. 7.1.b) y 33.4. b) de la Ley de Empleo, que prohíben el cobro a las personas trabajadoras

\footnotetext{
${ }^{20}$ CUESTA PASTOR, P., Delitos Obstáculo. Tensión entre Política Crimininal y Teoría del Bien Jurídico, Comares, Granada, 2002, p. 117-121.

${ }^{21}$ Arroyo Zapatero considera que en el precepto penal predomina el interés colectivo, que está representado por el mercado de trabajo, frente al interés individual de las personas trabajadoras. Asimismo, sostiene que lo esencial del tráfico ilegal de mano de obra reside en la prohibición de actos de colocación al margen de los servicios de empleo. ARROYO ZAPATERO, L., Manual de Derecho Penal, Praxis, Barcelona, 1988, p. 41.

${ }^{22}$ En este sentido, entre otros, PÉREZ MANZANO, M., "Delitos contra los derechos de los trabajadores", Relaciones Laborales, 1997, n 3, p. 129.

${ }^{23}$ La disociación de quien emplea que tiene lugar en la cesión de personas trabajadoras, requiere identificar con claridad a quien emplea realmente a las personas trabajadoras, lo cual implica una superación de la apariencia empresarial, como reacción de la legislación para garantizar a las personas trabajadoras que sus derechos son protegidos frente al empresariado real. Véase RODRIGUEZ RAMOS, M. J., La cesión ilegal de trabajadores tras la reforma de 1994, Tecnos, Madrid, 1995, p. 69.
} 
por las acciones realizadas para su colocación, incumplimientos tipificados por el ordenamiento sancionador laboral, concretamente en el art. 18.2.e) LISOS.

Tratamos de enlazar dos disciplinas del ordenamiento jurídico español, la laboral y la penal, respecto de un hecho, el tráfico ilegal de mano de obra, en el entendimiento de que el bien jurídico protegido "está constituido por un conjunto de intereses concretos y generales que protegen la indemnidad de la propia relación laboral mediante la sanción de conductas que atentan contra los derechos y condiciones laborales de los trabajadores" 24 . Hecho que afecta al interés del Estado por controlar el correcto funcionamiento del mercado laboral, que ha de contar con una protección efectiva por parte de los ordenamientos laboral y penal, dada su relevancia para mantener el "Estado de bienestar", en un mundo globalizado donde la descentralización productiva es un fenómeno generalizado en el que se debe equilibrar el interés empresarial de flexibilidad con el de seguridad que reclaman las personas trabajadoras (flexiseguridad) ${ }^{25}$. La interposición laboral, de forma ilegal, incide de manera directa en el mercado laboral, así como en los derechos de las personas trabajadoras, ya que se rompe la confianza e integridad de las relaciones laborales por la irrupción de un nuevo actor que interfiere fraudulentamente en la relación laboral ${ }^{26}$.

Para el estudio de las sentencias penales utilizamos un diseño observacional y no experimental, dentro de la perspectiva empírico-analítica, de base positivista racionalista (paradigma positivista), mediante el análisis documental de las sentencias sobre el tráfico ilegal de mano de obra. Como instrumento, para extraer la información de estas, diseñamos un protocolo de observación sistemática, "ad hoc" con las siguientes categorías: riesgo abstracto, explotación, contratación al margen de mecanismos legales, colocación irregular, cesión ilegal, habitualidad, lucro, nacionales y extranjeros y dolo.

Queremos indicar entre las limitaciones que hemos detectado, en este proceso de investigación, los escasos estudios encontrados sobre tráfico ilegal de mano de obra y su vertiente en el ámbito jurídico laboral ${ }^{27}$.

\footnotetext{
${ }^{24}$ STS de 10 de marzo de 2005, ${ }^{\circ} 321 / 2005$.

${ }^{25}$ La doctrina científica más autorizada considera el término "flexiseguridad" un neologismo que "alude a un modelo de articulación y ordenación de las relaciones laborales que aspira a conjugar un elevado grado de flexibilidad en el mercado laboral (contrataciones y despidos más fáciles, rápidos y poco gravosos, movilidad del personal, retribuciones variables, que permitan ajustar las condiciones laborales y las necesidades de mano de obra a las diferentes coyunturas) con una adecuada y permanente protección al trabajador desempleado (subsidios, indemnizaciones) y una eficaz política de empleo (disminuyendo los periodos de inactividad, propiciando la formación profesional permanente)" en CAVAS MARTÍNEZ, F., "El Derecho Social ante la crisis", Aranzadi social, 2008, n. 19., p. 2.

${ }^{26}$ Es fundamental destacar las palabras de la profesora López Aniorte: "entraríamos de lleno dentro de la denominada "versión patológica" de la descentralización productiva, encaminada a la reducción de costes empresariales mediante la interposición de un tercero en el lugar del verdadero empresario, con el fin de eludir la aplicación al trabajador de las normas que le resultan más favorables", en LÓPEZ ANIORTE, M ${ }^{\mathbf{a}}$. C., La descentralización productiva y su incidencia en la relación individual de trabajo, Laborum, Murcia, 2003.

${ }^{27}$ En ese sentido se manifiesta la SAP Granada de 10 de julio de 2017, no 368/2017: "La delgada línea que separa el delito de la infracción laboral, no resuelta por la jurisprudencia hasta el momento dados los escasos pronunciamientos sobre esa concreta figura penal (vg., en la STS de 23 de octubre de 2014 en la que finalmente no se pronuncia), obligaría a acudir al principio de intervención mínima del Derecho Penal para
} 


\section{Investigación documental sobre el Tráfico ilegal de mano de obra}

Con objeto de conocer lo que la jurisprudencia penal considera que es el tráfico ilegal de mano de obra, examinamos los fundamentos jurídicos de las sentencias relativas al mismo. Observamos la doctrina laboral y penal-laboral para definir el trafico ilegal de mano de obra, recoger evidencias sobre su concepción, y poder aportar criterios que contribuyan a perseguir judicialmente el trafico ilegal de mano de obra.

\section{Metodología y procedimiento}

Como ha afirmado un sector de la doctrina ${ }^{28}$, el objeto de la metodología o estudio del método o métodos puede tenerse en cuenta para el conocimiento de una materia científica, bien con fines solo de investigación o bien con fines prácticos o de aplicación. Para conocer un camino se ha de empezar por identificar su punto de partida y de llegada, se plantean, ¿cómo sin saber de dónde se parte y a dónde se va, es posible encontrar el mejor camino que resulte transitable? Destacan la importancia de ocuparse de la metodología del Derecho porque al ponderar el jurista la materia jurídica, al construirla científicamente, entra necesariamente en relación con la realidad social con la que, en cierta medida, se vincula y se integra. El jurista, ya sea desde la teoría o desde la práctica, está trabajando con una materia que tiene un contenido humano, moral y social, que el Derecho debe tener en cuenta, pues es de la sociedad para la sociedad. Por ello, hay que hacerlo comprensible para la ciudadanía, lo que requiere efectuar una función educadora, pedagógica, con objeto de contribuir a su aprendizaje en materia jurídica. Como indica Marx, "mi propia existencia es una actividad social, por esta razón, lo que yo mismo produzco lo produzco para la sociedad y con la conciencia de actuar como ser social" ${ }^{29}$. He ahí la importancia de la metodología, como camino para establecer un orden en la construcción de conocimientos y exponerlos posteriormente de manera clara. La "verdad" está ahí para construirla, cimentando "verdades" cada vez más complejas en procesos de reflexión infinitos.

La metodología utilizada en esta investigación corresponde a la investigación documental, "análisis detallado de una situación específica, apoyándose estrictamente en documentos confiables y originales" 30 , como son las normas jurídicas, las resoluciones judiciales y los textos doctrinales, siendo estas nuestras principales fuentes documentales.

exigir en el empresario que obrase de tal manera un plus en su conducta que justificase su mayor reprochabilidad".

28 Véase HERNANDEZ GIL, A., "Metodología de la ciencia del Derecho", Obras completas, vol. V, Espasa Calpe, Madrid, 1988, pp. 9, 30 y 60.

${ }^{29}$ FROMM, E., Marx y su concepto del hombre, $3^{\mathrm{a}}$ reimpresión, Fondo de cultura económica, México, 1970, p. 79.

${ }^{30}$ Véase: JÁÑEZ BARRIO, T., Metodología de la investigación en Derecho. Una orientación metódica, $4^{\text {a }}$ Ed., Caracas, Universidad Católica Andrés Bello, 2008, pág. 125. 


\subsection{Enfoque y diseño de la investigación}

El trabajo que presentamos forma parte de un estudio más amplio en el que se utiliza un enfoque mixto ${ }^{31}$ (cuantitativo no experimental y cualitativo), de dos diseños, observacional y fenomenológico. En este texto nos centramos en el primer diseño, que corresponde a la perspectiva empírico-analítica, de base positivista racionalista (paradigma positivista) que comprende preferentemente una metodología cuantitativa, en nuestro caso, no experimental, que empleamos para el estudio de las sentencias sobre tráfico ilegal de mano de obra; mediante el análisis documental de las mismas. Elaboramos un protocolo de observación sistemática para recoger los datos, de acuerdo con el concepto y requisitos del tráfico ilegal de mano de obra, contemplados en la doctrina académica. La persona que investiga "debe interesarse por los hechos y el conocimiento de los mismo nunca debe quedar interferido por lo subjetivo (las propias asunciones y valores)"32.

Dulzaides Iglesias y Molina Gómez ${ }^{33}$ definen el análisis documental como una forma de investigación técnica, un conjunto de operaciones intelectuales, que tratan de describir y mostrar los documentos de forma sistemáticamente unificada, para facilitar su recuperación. El tratamiento documental implica sacar partes científico-informativas de la fuente original, facilitando su recuperación y consulta.

Rodríguez de la Borbolla Camoyá ${ }^{34}$ defiende la necesidad de emplear "útiles metodológicos" y de revisar viejos paradigmas, mediante la formulación de hipótesis audaces y programas de investigación apropiados, como vía para lograr el progreso científico y el acercamiento a niveles de conocimiento que contribuyan a describir y explicar la realidad, y, en la medida de lo posible, transformarla por la influencia que tienen las aportaciones científicas sobre la misma. Afirma que la mejor vía para el conocimiento de la realidad es la utilización de una metodología correcta. Señala la importancia del "pluralismo metodológico a la hora de acercarme al conocimiento de la disciplina", porque es necesario para la investigación jurídica y, como afirma D'Antona ${ }^{35}$, se debe, primordialmente, a los siguientes hechos: a) la complejidad del Derecho y la conciencia de la crisis del mismo; b) la diversidad de las tareas del jurista; c) la interrelación de las ciencias del Derecho con otras ramas científicas, la cual es, a su vez,

\footnotetext{
${ }^{31}$ Véase CRESWELL, J. W., Research Design. Qualitative, Quantitative, and Mixed Methods Approaches, LA: Sage Publications, USA, 2014.

32 SABARIEGO PUIG, M., "La investigación educativa: génesis, evolución y características", BISQUERRA ALCINA, R., Metodología de la investigación educativa, La Muralla, Madrid, 2004., p. 71. ${ }^{33}$ DULZAIDES IGLESIAS, M. E. y MOLINA GÓMEZ, A. M., "Análisis documental y de información: dos componentes de un mismo proceso", Acimed, Vol. 12, n 2, 2004, pág. 1.

${ }^{34}$ Se puede consultar el trabajo de RODRIGUEZ DE LA BORBOLLA CAMOYÁN, J., "Algunas reflexiones sobre metodología de investigación en Derecho del Trabajo", Temas laborales: Revista andaluza de trabajo y bienestar social, 1994, $\mathrm{n}^{\circ} .31$, pp. 19 - 35.

${ }^{35}$ D'ANTONA, M., L'anomalia postpositivista del diritto del lavoro e la questione del metodo en Il metodo nella ricerca civilistica, Riv. Crit. Dir. Priv., n'. I-2, 1990, pp. 207-228, en concreto, p. 224: “l'adeguamento della metodologia alla complessità del diritto è una condizione, per così dire "etica", perché sia effettivamente possibile, all'interno della comunità scientifica, il controllo in forma dialogica de una determinata soluzione" ("la adaptación de la metodología a la complejidad del derecho es una condición, por así decirlo, "ética", para que sea efectivamente posible, dentro de la comunidad científica, el control en forma dialogada de una determinada solución").
} 
consecuencia y causa de la interrelación del Derecho con otras áreas de la vida social ${ }^{36}$; y d) la complejidad del objeto de la propia ciencia jurídica. Más de 20 años después, y en esta misma línea, Cruz Villalón ${ }^{37}$ manifiesta que, “con el paso del tiempo predominan las posiciones eclécticas o mejor dicho de pluralismo metodológico, donde domina la integración de los diferentes métodos y de las funciones de la investigación y de los métodos al efecto, a la vista de la complejidad que hoy en día adquiere la Ciencia jurídica. La orientación contemporánea requiere de un enfoque, a nuestro juicio, de orden más práctico, de abordaje de las diversas técnicas de investigación en lo concreto y de la experiencia acumulada en el desarrollo en el ámbito de lo laboral de los métodos de investigación". En este estudio hemos utilizado las cuatro grandes etapas del método científico: delimitación del problema, recogida de datos, análisis de datos e interpretación de resultados ${ }^{38}$, vinculados con el tráfico ilegal de mano de obra a través de las sentencias, teniendo presente, como fundamento, la doctrina científica.

Como se ha indicado anteriormente, optamos dentro del enfoque metodológico indicado por la observación como método de investigación. Los diseños observacionales se distinguen por su gran flexibilidad, actúan como modelos útiles para identificar datos que hay que conseguir, así como la forma de sistematizar y examinar. Siguiendo a Anguera ${ }^{39}$ "la metodología observacional en contextos naturales o habituales es un procedimiento científico que permite estudiar la ocurrencia de comportamientos perceptibles, de forma que se registren y cuantifiquen adecuadamente, lo cual implicará poder analizar relaciones de secuencialidad, asociación y covariación"; pues la observación, como técnica de investigación, permite trabajar con rigor, al exponer con precisión los elementos que se investigan, sin que se vean influenciados por las expectativas o predilecciones de quienes investigan.

En nuestro caso, recurrimos a la observación documental, que de acuerdo con Martín Marín 40 "se realiza analizando los documentos [...] actuales que recogen y reflejan fenómenos o datos de interés social", como las sentencias sobre tráfico ilegal de mano de obra, utilizando como técnica la observación sistemática de las sentencias, identificando

\footnotetext{
${ }^{36}$ En este sentido, en 1939, CARNELUTTI, F., Metodologia del diritto, CEDAM, Padova, 1990 (reedición de la edición de 1939), p. 28, afirmaba que "del diritto non si può fare né dalla parte di chi tocca comandare né dalla parte di chi tocca obbedire senza fare dei conti, cioè senza tener conto di altre regole, che sono le regole dell'economia, la quale sta a cavaliere, probabilmente, tra la sociologia e la psicologia. Ė dubbio che il diritto arrivi a dominare l'economia: ma è certo, invece, che l'economia regola il diritto: e non è rar il caso, purtroppo, che il diritto non operi perchè, da una parte o dall'altra, i conti sono stati sbagliati" ("del derecho no se puede hacer ni del lado de quien toca mandar ni del lado de quien toca obedecer sin hacer cuentas, es decir, sin tener en cuenta otras reglas, que son las reglas de la economía, la cual está al lado, probablemente, entre la sociología y la psicología. Es dudoso que el derecho llegue a dominar la economía; pero es cierto, en cambio, que la economía regula el derecho: y no es el caso, por desgracia, que el derecho no actúa porque, de un lado o del otro, las cuentas han sido equivocadas").

${ }^{37}$ CRUZ VILLALÓN, J., "La metodología de la investigación en el Derecho del Trabajo", Temas Laborales, 2016, $\mathrm{n}^{\circ} .132$, p. 75.

${ }^{38}$ ANGUERA, M". T., "Posibilidades y relevancia de la observación sistemática por el profesional de la Psicología", Papeles del psicólogo, vol. 31, nº 1, 2010, pp. 122-130.

${ }^{39}$ ANGUERA, M" ${ }^{\text {a }}$ T., "Posibilidades y relevancia de la observación sistemática por el profesional de la Psicología", cit., p. 122.

${ }^{40}$ MARTÍN MARÍN, B., Métodos de investigación y análisis de datos en ciencias sociales y de la salud, Pirámide, Madrid, 2011, p. 176.
} 
en ellas los elementos relativos al tráfico ilegal de mano de obras y a sus requisitos, y reflejamos los datos a través del protocolo de observación sistemática, elaborado a tal efecto y asentado en la doctrina. Conforme manifiestan Massot Lafon, Dorio Alcaraz y Sabariego Puig ${ }^{41}$, "el análisis documental es una actividad sistemática y planificada que consiste en examinar documentos ya escritos que abarcan una amplia gama de modalidades. Los documentos son una fuente bastante fidedigna y práctica para revelar los intereses y las perspectivas de quienes los han escrito".

\subsection{Participantes y contexto}

Cruz Villalón ${ }^{42}$ sostiene que "el método de investigación jurídica debe proceder a la contextualización de la norma: sus antecedentes históricos, su evolución, las razones del cambio legislativo, la evolución del contexto social, económico o político que determina los cambios de las reglas jurídicas, etc.”. Nos situamos en el contexto social español, en el que tiene lugar el tráfico ilegal de mano de obra, que afecta a personas extranjeras y nacionales, lo mismo a hombres que a mujeres, y que comprende tantos aspectos jurídicos laborales como penales.

En nuestro caso, como participantes tenemos 15 sentencias penales sobre tráfico ilegal de mano de obra, una vez seleccionadas de acuerdo con los criterios de inclusión y exclusión establecidos. En la Tabla 1 se exponen dichas sentencias, su distribución entre las Audiencias Provinciales (AP) y el Tribunal Supremo (TS), del orden penal, así como por los años en los que fueron dictadas.

\section{Tabla 1}

Distribución de sentencias sobre tráfico ilegal de mano de obra

\begin{tabular}{|l|l|}
\hline 1 & SAP Girona $15 / 10 / 1998\left(\mathrm{n}^{\mathrm{o}} 407 / 1998\right)$ \\
\hline 2 & SAP Girona $10 / 11 / 1998\left(\mathrm{n}^{\mathrm{o}} 442 / 1998\right)$ \\
\hline 3 & SAP Barcelona $15 / 12 / 1998\left(\mathrm{n}^{\circ}\right.$ proc. $\left.334 / 1996\right)$ \\
\hline 4 & SAP Las Palmas $31 / 07 / 1999\left(\mathrm{n}^{\mathrm{o}} 137 / 1999\right)$ \\
\hline 5 & SAP Burgos $29 / 10 / 2001\left(\mathrm{n}^{\mathrm{o}}\right.$ rec. $\left.464 / 1999\right)$ \\
\hline 6 & SAP Huelva $22 / 05 / 2004\left(\mathrm{n}^{\mathrm{o}} 134 / 2004\right)$ \\
\hline 7 & STS $10 / 03 / 2005\left(\mathrm{n}^{\mathrm{o}} 321 / 2005\right)$ \\
\hline 8 & SAP Huelva $7 / 11 / 2005\left(\mathrm{n}^{\mathrm{o}} 27 / 2005\right)$ \\
\hline 9 & SAP Alicante $21 / 03 / 2006\left(\mathrm{n}^{\mathrm{o}} 14 / 2006\right)$ \\
\hline 10 & SAP Huelva $23 / 03 / 2006\left(\mathrm{n}^{\mathrm{o}} 77 / 2006\right)$ \\
\hline 11 & SAP Huelva $17 / 04 / 2007\left(\mathrm{n}^{\circ} 84 / 2007\right)$ \\
\hline 12 & SAP Madrid $8 / 01 / 2008\left(\mathrm{n}^{\circ} 10 / 2008\right)$ \\
\hline
\end{tabular}

${ }^{41}$ MASSOT LAFON, I., DORIO ALCARAZ, I. y SABARIEGO PUIG, M., Métodos de investigación cualitativa. Metodología de la investigación educativa, La Muralla, Madrid, 2009, p. 349.

42 CRUZ VILLALÓN, J., "La metodología de la investigación en el Derecho del Trabajo", Temas Laborales, cit., p. 81. 


\begin{tabular}{|l|l|}
13 & SAP Barcelona $3 / 02 / 2009\left(n^{\circ} 53 / 2009\right)$ \\
\hline 14 & SAP Coruña $11 / 11 / 2013\left(n^{\circ} 268 / 2013\right)$ \\
\hline 15 & SAP Tarragona 3/11/2014 (n ( $\left.^{\circ} 422 / 2014\right)$ \\
\hline
\end{tabular}

\subsection{Recogida de información: instrumentos y procedimientos}

Una vez efectuada la búsqueda de las sentencias, en la base de datos de Aranzadi Instituciones y del CENDOJ. Instauramos un criterio de inclusión para la selección de las mismas, que contemplaba el término "tráfico ilegal". Registradas las sentencias que lo contenían, en total, 56, examinamos, dentro de cada una, "mano de obra" y después "312.1", y eliminamos 41 sentencias, seleccionadas previamente por no analizar el tipo penal del 312.1 CP, pues solo era referenciado o, en ocasiones, como, por ejemplo, las sentencias de SAP Valladolid de 26 de febrero de 2004, n 59/2004, y SAP Málaga de 3 de diciembre de 2004, n 674/2004, se han excluido porque, además de no analizar el tipo penal, manifiestan que el $312.1 \mathrm{CP}$ presupone la intervención en la captación de trabajadores al margen de los mecanismos previstos para la misma por la ley y relacionan captación al margen de los mecanismos legales con tramitación del permiso de residencia. Por consiguiente, analizamos 15 sentencias penales, a 31 marzo de 2021. Después, efectuamos el vaciado de datos, de forma manual, agregando cada hallazgo al registro de observación sistemática, siguiendo las dimensiones indicadas, anteriormente.

Además de la exploración efectuada para las sentencias, realizamos una búsqueda selectiva de bibliografía sobre el tráfico ilegal de mano de obra y de otros documentos que incluyeran información relevante sobre nuestra investigación. Para obtenerla utilizamos para las normas jurídicas, el Código Penal y la normativa laboral; para los textos doctrinales, el buscador Xabio, de la Biblioteca digital de la Universidad de Murcia, y Dialnet.

\subsection{Instrumentos y procedimiento}

En primer lugar, se procedió a contextualizar el problema mediante la revisión de las fuentes documentales, confeccionando el apartado doctrinal que fundamenta esta investigación, en el que se contempla los antecedentes y el estado actual de la cuestión, afirmando la importancia y la necesidad, desde el ámbito jurídico, del tema objeto de estudio.

A continuación, analizamos los instrumentos más pertinentes para estudiar la información, pues como expresa Cruz Villalón ${ }^{43}$, "la actividad de investigación en todos los campos del saber es el consistir en una labor que pretende aproximarse al conocimiento de la realidad en sus muy diferentes facetas". En este sentido, sigue afirmando que la metodología de cada ciencia es ante todo "la reflexión de esta ciencia sobre su propio proceder, sobre los modos de pensamiento y medios de conocimiento de que se sirve".

\footnotetext{
${ }^{43}$ CRUZ VILLALÓN, J., "La metodología de la investigación en el Derecho del Trabajo", cit., p. 76. 
Finalmente, construimos un protocolo de observación sistemática para extraer la información relevante sobre el tráfico ilegal de mano de obra.

\subsubsection{Protocolo de Observación Documental Sistemático (PODS)}

Construimos ad hoc el citado protocolo para el análisis documental, de acuerdo con las aportaciones de la doctrina académica sobre tráfico ilegal de mano y con las directrices metodológicas para el diseño de instrumentos ${ }^{44}$.

El instrumento lo integran 9 dimensiones, además de los datos de identificación, en las que se exploran: 1. Riesgo abstracto; 2. Explotación; 3. Contratación al margen de mecanismos legales; 4. Colocación irregular; 5. Cesión ilegal; 6. Habitualidad; 7. Lucro; 8. Nacionales y extranjeros; y, 9. Dolo.

\section{Análisis de los resultados sobre las sentencias}

Exponemos los resultados de la investigación de acuerdo con los objetivos, de modo que se incorpora un epígrafe para resolver cada uno.

Objetivo 1: Identificar los elementos significativos en los fundamentos jurídicos de cada una de las sentencias sobre tráfico ilegal de mano de obra.

A continuación, presentamos, en cada una de las sentencias, las diferentes categorías (elementos) contempladas en el protocolo de observación sistemática (Figura 1).

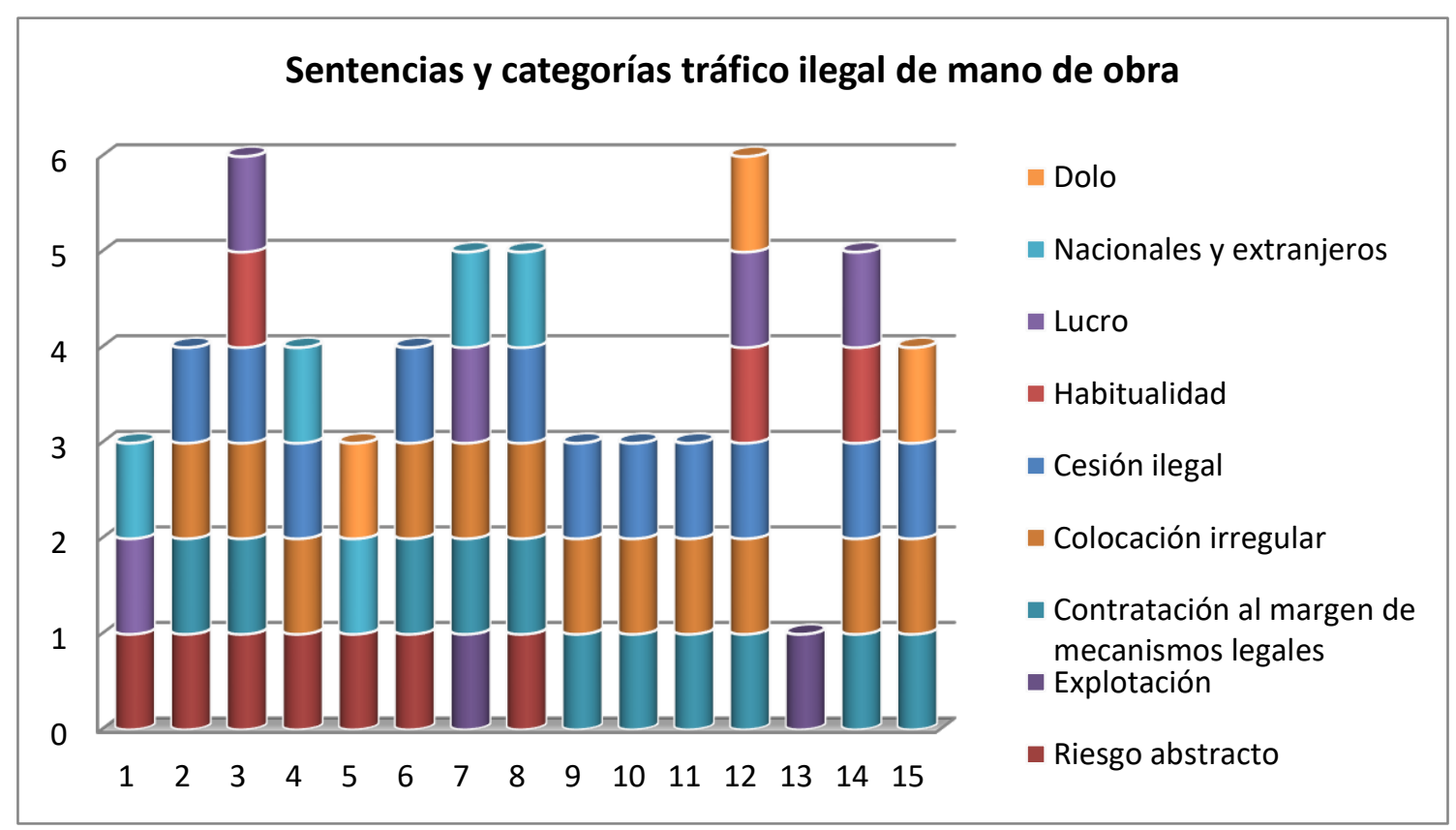

Figura 1. Sentencias y categorías vinculadas al tráfico ilegal de mano de obra

44 ANGUERA, Ma. T., "La observación”, en MORENO ROSSET, C. (Ed.), Evaluación psicológica. Concepto, proceso y aplicación en las áreas del desarrollo y de la inteligencia, Sanz y Torres, Madrid, 2005, pp. 255-292. ANGUERA, M . T., "Posibilidades y relevancia de la observación sistemática por el profesional de la Psicología”, cit., pp. 122-130. 
Podemos observar que no todas las sentencias contemplan las mismas categorías, por ejemplo, aunque tenemos dos sentencias que recogen seis categorías ( $\mathrm{n}^{\mathrm{o}} 3$ y 12), no coinciden las mismas. Sin embargo, sí coinciden al considerar que debe existir lucro y en que el delito de tráfico ilegal de mano de obra sanciona la contratación de personas trabajadoras que se realice al margen de la normativa reguladora, distinguiéndose dos conductas típicas: la cesión ilegal de mano de obra y la colocación laboral irregular, este ultimo aspecto también lo contemplan las sentencias $\mathrm{n}^{\mathrm{o}} 2,3,6,9,10,11$ y 15 .

Respecto a la explotación, esta categoría es contemplada en dos sentencias ( $\mathrm{n}^{\mathrm{o}} 7$ y 13 ), siendo una de ellas un pronunciamiento del TS, que señala que el centro de la acción típica es la explotación de la persona empleada, que no guarda relación con la sanción de un supuesto laboral agravado de cesión ilegal o colocación irregular de mano de obra.

Tabla 2

Sumatorio de categorías en cada sentencia

\begin{tabular}{|c|c|c|c|c|c|c|c|c|c|c|c|}
\hline NÚMERO & $\begin{array}{l}\text { Sentencias/ } \\
\text { Categorías }\end{array}$ & $\begin{array}{c}\text { Riesgo } \\
\text { abstracto }\end{array}$ & Explotación & $\begin{array}{c}\text { Contratación } \\
\text { al margen de } \\
\text { mecanismos } \\
\text { legales }\end{array}$ & $\begin{array}{l}\text { Colocación } \\
\text { irregular }\end{array}$ & $\begin{array}{c}\text { Cesión } \\
\text { ilegal }\end{array}$ & Habitualidad & Lucro & $\begin{array}{c}\text { Nacionales } \\
y \\
\text { extranjeros }\end{array}$ & Dolo & $\begin{array}{c}\text { SUMATORIO } \\
\text { DE } \\
\text { CATEGORÍAS } \\
\text { EN CADA } \\
\text { SENTENCIA }\end{array}$ \\
\hline 1 & $\begin{array}{l}\text { SAP GI } \\
15 / 10 / 1998\end{array}$ & 1 & & & & & & 1 & 1 & & 3 \\
\hline 2 & $\begin{array}{l}\text { SAP GI } \\
10 / 11 / 1998\end{array}$ & 1 & & 1 & 1 & 1 & & & & & 4 \\
\hline 3 & $\begin{array}{l}\text { SAP BCN } \\
15 / 12 / 1998\end{array}$ & 1 & & 1 & 1 & 1 & 1 & 1 & & & 6 \\
\hline 4 & $\begin{array}{l}\text { SAP Las } \\
\text { Palmas } \\
31 / 07 / 1999\end{array}$ & 1 & & & 1 & 1 & & & 1 & & 4 \\
\hline 5 & $\begin{array}{l}\text { SAP Burgos } \\
29 / 10 / 2001\end{array}$ & 1 & & & & & & & 1 & 1 & 3 \\
\hline 6 & $\begin{array}{l}\text { SAP Huelva } \\
22 / 05 / 2004\end{array}$ & 1 & & 1 & 1 & 1 & & & & & 4 \\
\hline 7 & $\begin{array}{l}\text { STS } \\
10 / 03 / 2005\end{array}$ & & 1 & 1 & 1 & & & 1 & 1 & & 3 \\
\hline 8 & $\begin{array}{l}\text { SAP Huelva } \\
7 / 11 / 2005\end{array}$ & 1 & & 1 & 1 & 1 & & & 1 & & 5 \\
\hline 9 & \begin{tabular}{|l|} 
SAP Alicante \\
$21 / 03 / 2006$
\end{tabular} & & & 1 & 1 & 1 & & & & & 3 \\
\hline 10 & $\begin{array}{l}\text { SAP Huelva } \\
23 / 03 / 2006\end{array}$ & & & 1 & 1 & 1 & & & & & 3 \\
\hline 11 & $\begin{array}{l}\text { SAP Huelva } \\
17 / 04 / 2007\end{array}$ & & & 1 & 1 & 1 & & & & & 3 \\
\hline 12 & $\begin{array}{l}\text { SAP Madrid } \\
8 / 01 / 2008\end{array}$ & & & 1 & 1 & 1 & 1 & 1 & & 1 & 6 \\
\hline 13 & $\begin{array}{l}\text { SAP Barcelona } \\
3 / 02 / 2009\end{array}$ & & 1 & & & & & & & & 1 \\
\hline 14 & $\begin{array}{l}\text { SAP Coruña } \\
11 / 11 / 2013\end{array}$ & & & 1 & 1 & 1 & 1 & 1 & & & 5 \\
\hline 15 & $\begin{array}{l}\text { SAP Tarragona } \\
3 / 11 / 2014\end{array}$ & & & 1 & 1 & 1 & & & & 1 & 4 \\
\hline
\end{tabular}


La interpretación judicial considera prácticamente de forma unánime que el trafico ilegal de mano de obra sanciona la contratación de personas trabajadoras que se realice al margen de la normativa reguladora, distinguiéndose dos conductas típicas: la cesión ilegal de mano de obra y la colocación laboral irregular, coincidiendo con la interpretación académica. También consideran que es un delito que afecta tanto a personas nacionales como extranjeras. Manifiestan que nos encontramos ante un delito de riesgo abstracto por lo que el bien jurídico es entendido de diferentes formas ${ }^{45}$.

Desde una perspectiva crítica, la jurisprudencia penal refleja graves incorrecciones; particularmente, denunciamos las consecuencias de su alejamiento de la doctrina científica sobre tráfico ilegal de mano de obra, al declarar el Tribunal Supremo, en su sentencia de 10 de marzo de 2005, que "el elemento central de esta conducta delictiva lo constituye la explotación del trabajador”. La inadecuada aplicación del precepto penal puede generar un conflicto respecto del delito de trata de personas, contemplado en el art. 177 bis $\mathrm{CP}$, que tiene entre sus finalidades la explotación laboral.

La jurisprudencia penal también ha considerado, por un lado, que el rigor de la pena imposibilita identificar el tráfico ilegal de mano de obra con la simple contratación ilegal de personas trabajadoras, con la mera intermediación ilegal en el mercado de trabajo, o con la cesión ilegal de personas trabajadoras. En general, los órganos judiciales manifiestan la necesidad de que exista un deslinde adecuado y eficaz entre el tipo penal y la mera infracción administrativa laboral ${ }^{46}$. En nuestra opinión, solo es posible hablar con propiedad de tráfico ilegal de mano de obra, cuando se incida en la relación laboral de las personas trabajadoras en el contexto del mercado laboral; no debiendo aplicarse este tipo penal cuando se utilice a las personas trabajadoras como un objeto, es decir, cuando se persiga la explotación de estas. Con la punición del tráfico de mano de obra se trataría de evitar que se comercie con la relación laboral sin respetar los más esenciales principios de la dignidad humana ${ }^{47}$. Con ello, se reforzaría la importancia que tiene el

\footnotetext{
${ }^{45}$ Se ha señalado que los bienes jurídicos protegidos son, por una parte, el derecho al acceso al puesto de trabajo de quienes demandan empleo que no han sido ilícitamente colocados y, por otra parte, el propio derecho de las personas trabajadoras victimas de tráfico ilegal. En este sentido, MARTINEZ-BUJÁN PÉREZ, C., Derecho penal económico y de la empresa. Parte especial, $6^{a}$ ed., Tirant lo Blanch, Valencia, 2019 , p. 866.

${ }^{46}$ SAP Tarragona de 3 de noviembre, $n^{\circ} 422 / 2014$, manifestó que "tras la nueva regulación introducida por el CP 1995 y la modificación de la normativa sancionadora laboral, la doctrina penalista ha venido discutiendo si el delito previsto en el art. 312.1 respeta el principio de ofensividad penal y si, aun admitiendo lo anterior, en la actividad de tráfico ilegal hay que entender incluidas, además de la conducta de cesión ilegal de trabajadores, la de colocación irregular. En este sentido, debe recordarse que se está en presencia de una infracción destinada a salvaguardar el buen funcionamiento del mercado laboral, en concreto, de las normas relativas a la contratación laboral".

${ }^{47}$ STS 18 de mayo de 1981, nº 670/1981. En este sentido, CARBONEL MATEU, J.C. y GONZALEZ CUSSAC, J.L., consideran que en el tráfico ilegal de mano de obra existe un aprovechamiento de las personas trabajadoras, al enriquecerse mediante la actividad que estas realizan, en VIVES ANTON, T.S (coord.), Comentarios al Código Penal de 1995, Tirant lo Blanch, Valencia, 1996. Lascuraín Sánchez refuta la identificación tradicional del tráfico ilegal de mano de obra con la simple intermediación laboral ilegal o con la cesión ilegal. Entiende que es preciso identificar el precepto con la utilización involuntaria de las prestaciones laborales de las personas trabajadoras, afectando a su propia dignidad. LASCURAÍN SÁNCHEZ, J. A., "Los delitos contra los derechos de los trabajadores:lo que sobra y lo que falta", Anuario de Derecho Penal y Ciencias Penales, $\mathrm{n}^{\circ}$ LVII, 2004, pp. 44-45.
} 
mercado laboral y quienes lo integran. Debemos destacar que algunos pronunciamientos introducen, como elementos significativos para diferenciar la infracción administrativo laboral de la penal, requisitos de habitualidad, lucro ${ }^{48}$ o dolo.

Tras el estudio de las sentencias cabe destacar que existen distintas interpretaciones en cuanto al bien jurídico protegido en el art. 312.1 CP, lo que presentamos en la siguiente tabla:

Tabla 3

Bien jurídico protegido

\begin{tabular}{|c|l|}
\hline Sentencias/Categoría & \multicolumn{1}{|c|}{ Bien jurídico } \\
\hline SAP GI 15/10/1998 & Ejercicio de los derechos de los trabajadores \\
\hline SAP GI 10/11/1998 & $\begin{array}{l}\text { Interés colectivo (Mercado de trabajo) y Derechos de los trabajadores } \\
\text { como colectivo (económicos, libertad, seguridad y dignidad) }\end{array}$ \\
\hline SAP BCN 15/12/1998 & $\begin{array}{l}\text { Expectativa de empleo trabajadores o interés de los trabajadores a } \\
\text { través exigencia de control administrativo }\end{array}$ \\
\hline SAP Las Palmas 31/07/1999 & Proteger a los trabajadores de una nueva forma de explotación \\
\hline SAP Burgos 29/10/2001 & Ejercicio de los derechos de los trabajadores \\
\hline SAP Huelva 22/05/2004 & $\begin{array}{l}\text { Interés colectivo (Mercado de trabajo) y Derechos de los trabajadores } \\
\text { como colectivo (económicos, libertad, seguridad y dignidad) }\end{array}$ \\
\hline STS 10/03/2005 & $\begin{array}{l}\text { Conjunto de intereses concretos y generales que protegen la } \\
\text { indemnidad relación laboral mediante la sanción de conductas que } \\
\text { atentan contra los derechos y condiciones laborales de los trabajadores }\end{array}$ \\
\hline SAP Huelva 7/11/2005 & $\begin{array}{l}\text { Interés colectivo (Mercado de trabajo) y Derechos de los trabajadores } \\
\text { como colectivo (económicos, libertad, seguridad y dignidad) }\end{array}$ \\
\hline SAP Alicante 21/03/2006 & No menciona \\
\hline SAP Huelva 23/03/2006 & No menciona \\
\hline SAP Huelva 17/04/2007 & No menciona \\
\hline SAP Madrid 8/01/2008 & No menciona \\
\hline SAP Barcelona 3/02/2009 & $\begin{array}{l}\text { Conjunto de intereses concretos y generales que protegen la } \\
\text { indemnidad relación laboral mediante la sanción de conductas que } \\
\text { atentan contra los derechos y condiciones laborales de los trabajadores }\end{array}$ \\
\hline SAP Tarragona 3/11/2014 & $\begin{array}{l}\text { Conjunto de intereses concretos y generales que protegen la } \\
\text { indemnidad relación laboral mediante la sanción de conductas que } \\
\text { atentan contra los derechos y condiciones laborales de los trabajadores }\end{array}$ \\
\hline $\begin{array}{l}\text { Puesta en peligro del derecho al puesto de trabajo de otros asalariados u } \\
\text { obstaculización material de las políticas públicas de empleo }\end{array}$ \\
\hline SAna 11/11/2013
\end{tabular}

${ }^{48}$ Con objeto de reducir el ámbito de prohibición del delito, un sector de la doctrina ha entendido que "traficar" exige ánimo de lucro, en este sentido, CARBONELL MATEU, J.C. y GONZÁLEZ CUSSAC, J. L., en Vives Antón (Coord.), Comentarios al Código Penal de 1995, cit., p. 1551. Algunos autores han considerado que, además de lucro, debe existir habitualidad. En este sentido, PÉREZ MANZANO, M., "Delitos contra los derechos de los trabajadores", Relaciones Laborales, n 3, 1997, pp. 29. 


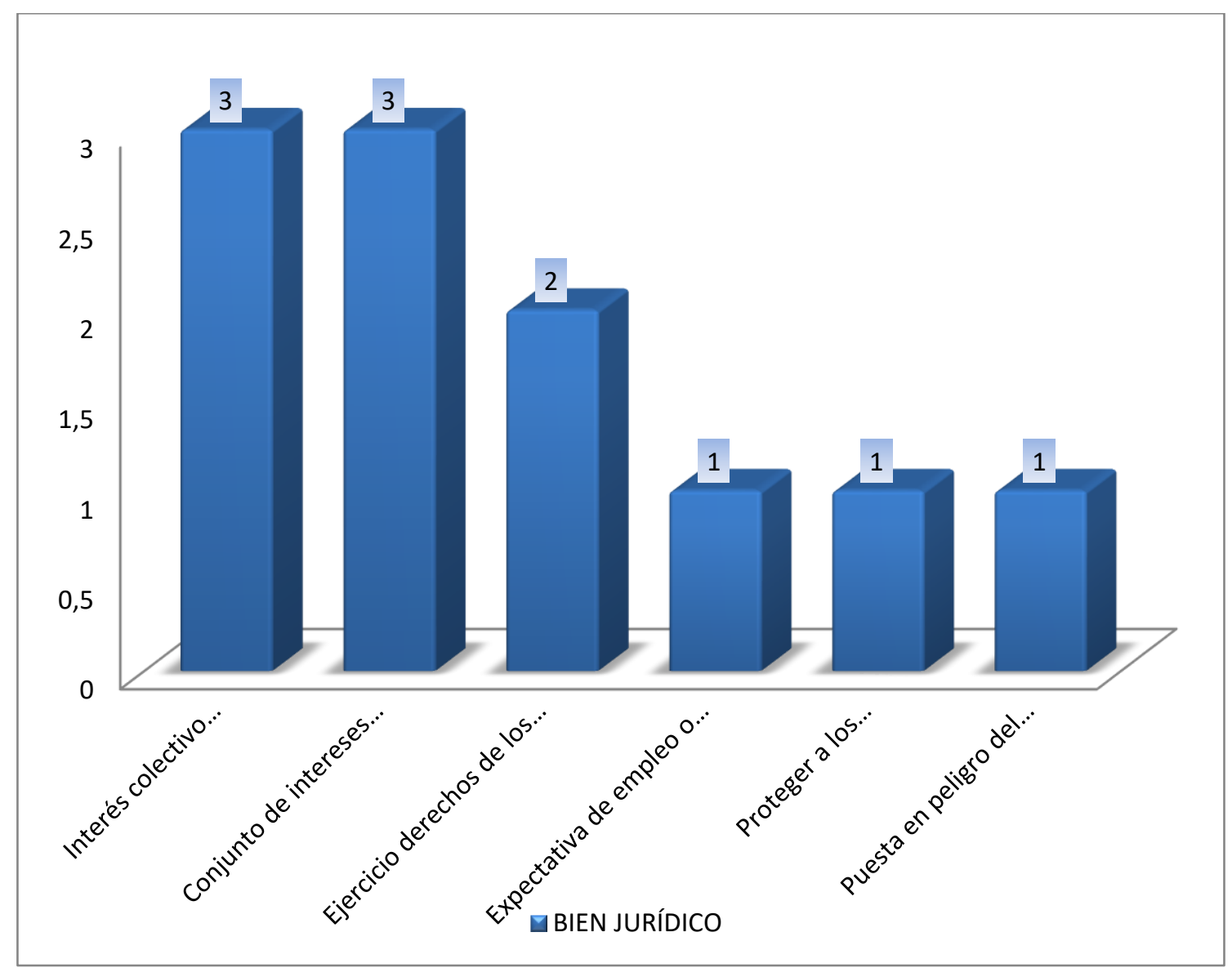

Figura 3. Sumatorio Bien jurídico protegido

El Alto Tribunal ha interpretado que el bien jurídico protegido está constituido por un conjunto de intereses concretos y generales, que protegen la indemnidad de la relación laboral mediante la sanción de conductas, que atentan contra los derechos y condiciones laborales de las personas trabajadoras. Ahora bien, se debe fundamentar doctrinalmente el tipo penal para no caer en una posible arbitrariedad legislativa de la que adolecen ciertos delitos de riesgo abstracto. Situación que no ocurre en aquellos supuestos donde existe una lesión directa sobre la victima ${ }^{49}$. Este hecho lo podemos observar en el tipo analizado, donde la lesión directa sobre la victima la contempla el art. 177 bis y, la protección del delito de riesgo abstracto, al afectar la conducta al mercado laboral, la encontramos en el art. 312.1 CP, es decir, por un lado se protege la integridad de la persona y por otro el resultado de su actividad humana, el trabajo, integrado en un ámbito mayor y colectivo, el mercado de trabajo observando la regulación laboral que sanciona ciertos fenómenos interpositorios (la colocación laboral irregular y la cesión ilegal de mano de obra). Por tanto, en nuestra opinión, un primer elemento diferenciador del delito de tráfico ilegal de mano de obra respecto de la infracción administrativa debe ser que el sujeto activo actúa sobre una pluralidad de sujetos pasivos, ya que este hecho incide

\footnotetext{
${ }^{49}$ BAYLOS GRAU, A. y TERRADILLOS BASOCO, J. M., Derecho penal del trabajo, $2^{\text {a }}$ Edición revisada, Trotta, Madrid, 1997, p. 84; y, SAP de 1
} 
notablemente sobre el mercado laboral superando la mera infracción administrativa que se debe aplicar, en nuestra opinión, en casos singulares.

\section{Conclusiones y propuestas}

Tras el análisis de los datos obtenidos comprobamos la pertinencia de incorporar diferentes y complementarias miradas metodológicas para comprender e interpretar los hechos jurídicos, en este caso, vinculados con el tráfico ilegal de mano de obra en España, en un mundo complejo, global y dinámico, en el que los avances de las tecnologías de la información y la comunicación favorecen el incremento de los fraudes, tanto en número como en sofisticación. Por ello, el ordenamiento jurídico tiene que aportar respuestas pertinentes y rigurosas para luchar activamente contra los mismos, adaptando el Derecho a las nuevas realidades sociales.

El tráfico ilegal de mano de obra es un delito que impacta sobre el mercado laboral, dado que, debido a la globalización económica, las empresas descentralizan su producción, la externalizan, lo que posibilita que haya personas que pretenden obtener, de forma engañosa, beneficios a costa de quienes realizan el trabajo.

La doctrina científica iuslaboralista y penal, que ha estudiado el delito de tráfico ilegal de mano de obra, al analizar el art. 312.1 CP, considera que se persigue la contratación de personas trabajadoras que se realice al margen de la normativa reguladora, distinguiéndose dos conductas típicas: la cesión ilegal de mano de obra y la colocación laboral irregular. Afirmación que se ve recogida en la mayoría de los fundamentos jurídicos de las sentencias estudiadas.

No obstante, después de diferentes reformas laborales, cabe considerar que el supuesto de hecho del tipo penal hace referencia, actualmente, a los supuestos de colocación en los que se cobra por los servicios de intermediación a la persona trabajadora; y la cesión ilegal de mano de obra o tráfico prohibido de mano de obra.

Sin embargo, el Tribunal Supremo ha declarado que "el elemento central de esta conducta delictiva lo constituye la explotación del trabajador". Interpretación que no compartimos pues el verbo nuclear (así lo reconoce expresamente el Alto Tribunal) es traficar, del cual no se desprende que la persona sea explotada. Hay que tener presente que nos hallamos ante un delito de riesgo abstracto, que sanciona versiones agravadas de cesión ilegal de mano de obra y colocación laboral irregular. En ambos supuestos, se perturba la relación laboral con resultados negativos sobre los derechos laborales y el mercado laboral.

Consideramos que la interpretación del TS no guarda relación con las infracciones administrativo-laborales que integra el tipo penal. Igualmente, esta interpretación puede originar un concurso de delitos, principalmente con el art. 177 bis CP. Por consiguiente, el delito debe entenderse como aquella situación en la que, además de vulnerarse los derechos laborales, estos atentan contra el interés del Estado en proteger el mercado laboral, constituyendo este un elemento de significatividad para determinar la ofensividad penal. Por consiguiente, la infracción administrativa debería reservarse para aquellos incumplimientos leves o imprudentes, en los que el sujeto no lleva a cabo la acción de 
forma habitual, no percibe beneficio económico por su acción ni la realiza incidiendo sobre una pluralidad de sujetos. Es necesario el cumplimiento de las exigencias de habitualidad en el actuar del sujeto activo. En estas actuaciones ilícitas, la habitualidad o persistencia continuada en la comisión de la infracción no debe ser un elemento agravante de la sanción administrativo-laboral, ex art. 39.7 LISOS, sino un elemento diferenciador clave entre la mera infracción administrativo-laboral y el delito.

Desde nuestro punto de vista no se puede plasmar un resultado sobre la integridad física del sujeto pasivo, sino que, con el cobro por los servicios de intermediación laboral a la persona trabajadora o cesión ilegal de mano de obra, se ven afectados una serie de intereses concretos y generales, que aquejan a un bien jurídico abstracto, como es la correcta contratación laboral, la indemnidad de la relación laboral dentro del mercado trabajo. Se preservan, en definitiva, ciertos derechos tanto de las personas trabajadoras como de las empleadoras, sus derechos económicos, su seguridad y su dignidad.

El tráfico de mano de obra tiene graves implicaciones sociales, pues perturba los derechos de las quienes trabajan y del empresariado que ejecuta sus compromisos en materia laboral y de Seguridad Social. También, puede tener consecuencias negativas en las economías nacionales, pues al no cumplir con la normativa laboral y de Seguridad Social vigente, no solamente se lesiona a quienes cumplen con sus obligaciones, sino que además incide sobre los recursos económicos del país. Así pues, tiene consecuencias para toda la sociedad, perturbando, a su vez, al resto de actores del mercado laboral que cumplen con la normativa vigente.

En nuestra opinión, se tutela principalmente el interés del Estado por controlar el mercado de trabajo y garantizar que la contratación laboral se efectúe mediante los mecanismos legales, respetando los derechos del personal empleado y de quienes emplean.

\section{Bibliografía}

ANGUERA, Ma. T., "La observación", en MORENO ROSSET, C. (Ed.), Evaluación psicológica. Concepto, proceso y aplicación en las áreas del desarrollo y de la inteligencia, Sanz y Torres, Madrid, 2005, pp. 255-292.

ANGUERA, M". T., "Posibilidades y relevancia de la observación sistemática por el profesional de la Psicología”, Papeles del psicólogo, vol. 31, nº 1, 2010, pp. 122-130.

ARROYO ZAPATERO, L., Manual de Derecho Penal, Praxis, Barcelona, 1988.

BAYLOS GRAU, A. y TERRADILlOS BASOCO, J. M., Derecho penal del trabajo, $2^{\text {a }}$ Edición revisada, Trotta, Madrid, 1997.

CARBONELL MATEU, J.C. y GONZÁLEZ CUSSAC, J. L., en Vives Antón (Coord.), Comentarios al Código Penal de 1995, Tirant lo Blanch, Valencia, 1996. 
CARDONA RUBERT, B. y CABEZA PEREIRO, J. El gran pacto social que debería esperar. LABOS Revista de Derecho del Trabajo y Protección Social, 2021, vol. 2, no 1, p. 124-136.

CARNELUTTI, F., Metodologia del diritto, CEDAM, Padova, 1990 (reedición de la edición de 1939).

CASTEL, R., Les metamorphoses de la question sociale. Chronique du salariat, Paris, Fayard, 1995.

CAVAS MARTÍNEZ, F., "El Derecho Social ante la crisis". Aranzadi social, no. 19, 2009.

CRESWELL, J. W., Research Design. Qualitative, Quantitative, and Mixed Methods Approaches, LA: Sage Publications, USA, 2014.

CRUZ VILLALÓN, J., "La metodología de la investigación en el Derecho del Trabajo", Temas Laborales, 2016, nº 132.

CUESTA PASTOR, P. Delitos Obstáculo. Tensión entre Política Crimininal y Teoría del Bien Jurídico, Comares, Granada, 2002.

D’ANTONA, M., L'anomalia postpositivista del diritto del lavoro e la questione del metodo en Il metodo nella ricerca civilistica, Riv. Crit. Dir. Priv., nº I-2, 1990, pp. 207228 .

DE RUGGIERO, G., El concepto del trabajo y su génesis histórica, La Pleyade, Buenos Aires, 1973.

DE VICENTE MARTÍNEZ, R., Derecho penal del trabajo: los delitos contra los derechos de los trabajadores y contra la Seguridad Social, Tirant lo Blanch, 2020.

DULZAIDES IGLESIAS, M. E. y MOLINA GÓMEZ, A. M., "Análisis documental y de información: dos componentes de un mismo proceso", Acimed, Vol. 12, no 2, 2004, pág. 1.

FROMM, E., Marx y su concepto del hombre, $3^{\mathrm{a}}$ reimpresión, Fondo de cultura económica, México, 1970.

GARCÍA ARÁN, M., en Córdoba Roda/García Arán (Dirs.), Comentarios al Código Penal. Parte Especial, Tomo I, Marcial Pons, Madrid, 2004.

GOLDIN, A., La libertad sindical y las iniciativas voluntarias; el caso de Jerzees de Honduras, en GORELlI HERNANDEZ, J., (coord.), El Derecho a la negociación colectiva" Liber Amicorum Profesor Antonio Ojeda Avilés, Colección Monografías de Temas Laborales, Consejo Andaluz de Relaciones Laborales, Junta de Andalucía, Sevilla, 2014.

GOLDIN, A., "La problemática laboral de la descentralización productiva y la transformación del Derecho del Trabajo", en MONEREO PÉREZ, J. L. y PERÁN QUESADA, S. (dirs.), La externalización productiva a través de la subcontratación empresarial, Comares, Granada, 2018. 
GUIRAO SORIANO, P., "La protección penal de los derechos del socio. Crítica y derecho comparado", en III Jornadas doctorales de la UM, EDITUM, Murcia, 2017.

HERNANDEZ GIL, A., "Metodología de la ciencia del Derecho”, Obras completas, vol. V, Espasa Calpe, Madrid, 1988.

JÁÑEZ BARRIO, T., Metodología de la investigación en Derecho. Una orientación metódica, $4^{\mathrm{a}}$ Ed., Caracas, Universidad Católica Andrés Bello, 2008.

LASCURAÍN SÁNCHEZ, J. A., "Los delitos contra los derechos de los trabajadores:lo que sobra y lo que falta", Anuario de Derecho Penal y Ciencias Penales, n LVII, 2004.

LÓPEZ ANIORTE, Ma . C., La descentralización productiva y su incidencia en la relación individual de trabajo, Laborum, Murcia, 2003.

MARTÍN MARÍN, B., Métodos de investigación y análisis de datos en ciencias sociales y de la salud, Pirámide, Madrid, 2011.

MARTINEZ-BUJÁN PÉREZ, C., Derecho penal económico y de la empresa. Parte especial, $6^{\mathrm{a}}$ ed., Tirant lo Blanch, Valencia, 2019.

MARTINEZ MORENO, C. "El riesgo de exclusión social de los trabajadores pobres: análisis de las reglas jurídicas conectadas con este nuevo fenómeno", en MORENO I GENÉ, J. (dir.), FERNÁNDEZ VILLAZÓN, L. A. (dir.), Crisis de empleo, integración y vulnerabilidad social, Thomson Reuters Aranzadi, Cizur Menor, Navarra, 2017, pp. 181-216.

MARZAL, A. (ed.). Crisis del estado del bienestar y derecho social. José María Bosch, 1997.

MASSOT LAFON, I., DORIO ALCARAZ, I. y SABARIEGO PUIG, M., Métodos de investigación cualitativa. Metodología de la investigación educativa, La Muralla, Madrid, 2009.

MATTES, H.; MATTES, H.; RODRÍGUEZ DEVESA, J. M., Problemas de derecho penal administrativo: historia y derecho comparado. Editoriales de Derecho Reunidas, 1979.

MONEREO PEREZ, J. L., "La garantía de los derechos de los trabajadores en la subcontratación empresarial, Derecho de las Relaciones Laborales, nº. 2, 2016.

NAVARRO CARDOSO, F., Los delitos contra los derechos de los trabajadores, Tirant lo Blach, Valencia, 1998.

PÉREZ MANZANO, M., "Delitos contra los derechos de los trabajadores”, Relaciones Laborales, $\mathrm{n}^{\circ}$ 3, 1997.

RODRÍGUEZ, S.A., Some comments on the use of Pearson's coefficient as an index of interobserver agreement. Revista Mexicana de análisis de conducta, 1984, 10 (2), pp. 137-160. 
RODRIGUEZ DE LA BORBOLLA CAMOYÁN, J., "Algunas reflexiones sobre metodología de investigación en Derecho del Trabajo", Temas laborales: Revista andaluza de trabajo y bienestar social, 1994, nº 31, pp. 19 - 35.

RODRIGUEZ-PIÑERO y BRAVO-FERRER, M., “Trabajadores pobres y Derecho del Trabajo, Relaciones Laborales, $\mathrm{n}^{\mathrm{o}}$.2, 2009.

RODRIGUEZ RAMOS, M. J., La cesión ilegal de trabajadores tras la reforma de 1994, Tecnos, Madrid, 1995.

RODRIGUEZ RODRIGUEZ, E., "La subrogación empresarial en los procesos de reversión de contratas y concesiones administrativas ante una administración pública digitalizada". Pertsonak eta Antolakunde Publikoak Kudeatzeko Euskal Aldizkaria= Revista Vasca de Gestión de Personas y Organizaciones Públicas, 2019, no 17, p. 54-69. SABARIEGO PUIG, M., "La investigación educativa: génesis, evolución y características”, BISQUERRA ALCINA, R., Metodología de la investigación educativa, La Muralla, Madrid, 2004.

SCHWAB, K. La cuarta revolución industrial. Debate, 2016.

TERRADILlos BASOCO, J. M., Derecho penal de la empresa, Trotta, Madrid, 1995.

VILLACAMPA ESTIARTE, C. y SALAT PAISAL, M., en Quintero Olivares (Dir.) Morales Prats (Coord.) Comentarios a la Parte Especial del Derecho Penal, 10 a ed., Aranzadi, Pamplona, 2015. 